\title{
Vulvoplastia pré ou pós-cobertura e sua influência na fertilidade
}

\section{Perineal repair either before or after breeding and its influence on fertility}

\author{
Eduardo Malschitzky, ${ }^{*}$ Petra Garbade, ${ }^{* *}$ Ricardo Macedo Gregory, ${ }^{* *}$ Rodrigo da Costa Mattos ${ }^{\star *}$
}

\begin{abstract}
Resumo
O presente estudo teve como objetivo comparar a taxa de prenhez de éguas PSC apresentando boa conformação perineal, natural ou corrigida cirurgicamente, no momento da cobertura com a taxa obtida em éguas com falhas no fechamento vulvar e cuja correção cirúrgica ocorreu somente após a ovulação. Foram utilizadas 293 éguas Puro Sangue de Corrida, sendo 47 virgens, 96 falhadas e $150 \mathrm{com}$ produto ao pé. Durante os exames de rotina para o controle folicular, a região perineal era avaliada quanto à sua conformação. Quando necessária, a sutura dos lábios vulvares era realizada o mais rapidamente possível, após a ovulação. Os diagnósticos de gestação foram realizados através de ultra-sonografia entre 12 e 14 dias após a ovulação. Foi observada diferença significativa $(p=0,072)$ entre as éguas com bom fechamento vulvar e com mau fechamento vulvar. Conclui-se que correções dos defeitos de períneo efetuadas antes do início do cio em que se efetuará a cobertura apresentam melhores resultados de prenhez do que quando a correção é realizada após a ovulação.
\end{abstract}

Palavras-chave: eqüinos, vulvoplastia, taxa de prenhez.

\begin{abstract}
The present study aimed to compare the pregnancy rate of thoroughbred mares showing good perineal conformation at breeding, either natural or surgically corrected, with the pregnancy rate of mares showing vulvar impairments corrected just after ovulation. The number of animals studied totalized 293, from which 47 were maiden, 96 were barren and 150 were foaling mares. Perineal conformation was examined at follicular control and, if necessary, surgical repair was performed immediately after ovulation. Pregnancy was detected by ultrasound 12 to 14 days after ovulation. Pregnancy rates were significantly different $(p=0,072)$ between mares with good and impaired perineal conformation. Better pregnancy rates were obtained when perineal repair was performed before the breeding cycle than after ovulation.
\end{abstract}

Keywords: equine, perineal repair, pregnancy rates.

\section{Introdução}

A espécie eqüina tem sido considerada como a de menor fertilidade dentre as espécies domésticas (Ginther, 1992)). No Puro Sangue de Corrida (PSC), onde a seleção de reprodutores e matrizes é feita exclusivamente com base na performance atlética, a fertilidade, um caráter determinado pela herança genética, além de fatores ambientais, pode ser ainda mais prejudicada. Tem sido observado que problemas como endometrites e defeitos de conformação perineal ocorrem dentro de certas famílias, assim como a subfertilidade, o que demonstra os efeitos deletérios da seleção por performance sobre o aspecto reprodutivo (Rossdale, 1997).

A importância da vulva como mecanismo de defesa contra infecções uterinas na égua foi ressaltada pela primeira vez por Caslick (1937), que descreveu também os bons resultados sobre a fertilidade obtidos com a realização da sutura dos lábios vulvares. A vulvoplastia é o procedimento mais freqüentemente realizado como forma de tratamento para problemas reprodutivos (Rossdale, 1997).
A conformação perineal sofre grande influência da idade, tendo sido demonstrado por Pascoe (1979) que éguas com boa conformação podem necessitar reparação vulvar com o avançar da idade e após certo número de partos. O autor demonstrou, também, a influência da condição corporal sobre o fechamento vulvar. Éguas em má condição corporal têm maior probabilidade de apresentar pneumovagina devido à redução do tecido adiposo na região vulvar.

Pascoe (1979) demonstrou ainda o efeito da conformação perineal da égua sobre a taxa de prenhez, sendo que as éguas classificadas como candidatas à vulvoplastia apresentaram um índice de prenhez significativamente menor do que aquelas que não necessitavam cirurgia, ou do que aquelas que já haviam sido suturadas anteriormente. A realização da sutura dos lábios vulvares até o nível do assoalho da pelve, em éguas com grande inclinação vulvar e grande abertura vulvar eleva a taxa de prenhez dessas éguas a níveis semelhantes aos obtidos em éguas cuja conformação não requer a correção cirúrgica. A realização da sutura dos lábios vulvares em até 48 horas após o parto melhorou signifi-

\footnotetext{
* M.Sc. Aluno de Doutorado em Ciências Veterinárias - UFRGS.

** Dr. Professor Adjunto Faculdade de Veterinária - UFRGS.

Endereço para correspondência: rcmattos@ufrgs.br.
} 
cativamente a taxa de prenhez (66\%) em éguas cobertas no cio do potro, em comparação com éguas suturadas somente após a cobertura no cio do potro (34\%) (Pascoe, 1993).

O presente estudo teve como objetivo comparar a taxa de prenhez de éguas PSC apresentando boa conformação perineal, natural ou corrigida cirurgicamente, no momento da cobertura, com a taxa obtida em éguas com falhas no fechamento vulvar e cuja correção cirúrgica ocorreu somente após a ovulação.

\section{Material e métodos}

\section{Animais}

Foram utilizadas 293 éguas Puro Sangue de Corrida, sendo 47 virgens, 96 falhadas e $150 \mathrm{com}$ produto ao pé. As éguas eram mantidas em regime de semi-confinamento, recebendo suplemento alimentar com aveia, ração comercial e feno de alfafa. A idade das éguas variou de 3 a 24 anos. Durante duas temporadas de monta foram acompanhados 344 ciclos estrais.

\section{Manejo reprodutivo}

Os animais foram submetidos à rufiação diária. Uma vez detectados sinais externos de cio, o trato reprodutivo das éguas foi examinado por palpação retal diária, acompanhada pelo exame ultra-sonográfico, a fim de detectar a ovulação e determinar o melhor momento para a cobertura. Nas éguas com produto ao pé, a rufiação foi iniciada no $5^{\circ}$ dia após 0 parto.

Durante os exames de rotina para o controle folicular, a região perineal foi avaliada quanto à sua conformação. As características de angulação da vulva, coaptação dos lábios vulvares e a distância entre a comissura vulvar superior e a linha do assoalho da pelve eram avaliadas e, desta forma, era determinada a necessidade ou não da realização de vulvoplastia. Portanto, as éguas foram divididas em dois grupos: a) éguas com fechamento vulvar adequado e b) éguas com falhas no fechamento vulvar.

Foi considerado como bom fechamento vulvar aquele em que a comissura superior da vulva encontrava-se abaixo ou ao mesmo nível da linha do assoalho da pelve, em que a vulva apresentasse posição vertical, e em que a musculatura vulvar firme permitisse uma perfeita coaptação dos lábios. As éguas que apresentavam falhas no fechamento vulvar foram submetidas a vulvoplastia imediatamente após a ovulação, através da técnica de Silva (1983).

Somente foram cobertas éguas que não apresentavam evidência clínica de endometrite durante os exames ginecológicos diários. As éguas que apresentaram sinais clínicos de endometrite foram tratadas e cobertas no cio seguinte, após a confirmação da cura do processo inflamatório.

\section{Diagnóstico de gestação}

Os diagnósticos de gestação foram realizados através de ultrasonografia entre 12 e 14 dias após a ovulação.

\section{Análise estatística}

As comparações de taxas de prenhez foram feitas através do teste do qui-quadrado.

\section{Resultados}

Durante duas temporadas reprodutivas foram acompanhados 344 ciclos estrais de 47 éguas virgens, 96 éguas falhadas e 150 éguas paridas. A idade média das éguas virgens, falhadas e com cria foi de 4,3 $\pm 0,9$ anos, 10,1 $\pm 3,9$ anos e 9,7 $\pm 3,7$ anos, respectivamente.

Pouco mais da metade das éguas falhadas $(51,2 \%)$ apresentavam deficiência no fechamento vulvar. Entre as éguas com cria e virgens, $44,1 \%$ e $40,0 \%$, respectivamente, necessitavam correção de má conformação perineal.

As taxas de prenhez para éguas em diferentes condições reprodutivas, em função da presença ou não de defeitos de conformação perineal, estão apresentadas na Tabela 1.

Tabela 1: Taxas de prenhez de éguas virgens, vazias e com potro ao pé em função da conformação perineal no momento da cobertura

\begin{tabular}{ccccc}
\hline & \multicolumn{4}{c}{ Fechamento vulvar } \\
\cline { 2 - 5 } Condição & \multicolumn{3}{c}{ Correto } & \multicolumn{2}{c}{ Incorreto } \\
\cline { 2 - 5 } reprodutiva & $\mathrm{n}$ & Prenhez (\%) & $\mathrm{n}$ & Prenhez (\%) \\
\hline Virgens & 39 & 71,7 & 26 & 73,1 \\
Falhadas & 61 & 59,0 & 64 & 46,8 \\
Com cria & 86 & 63,9 & 68 & 54,4 \\
TOTAL & $\mathbf{1 8 6}$ & $\mathbf{6 3 , 9 ^ { \mathbf { a } }}$ & $\mathbf{1 5 8}$ & $\mathbf{5 4 , 4 ^ { \mathbf { b } }}$ \\
\hline
\end{tabular}

$a, b(p=0,072)$ letras diferentes nas linhas representam diferenças significativas

Foi observada diferença significativa $(p=0,072)$ entre as éguas com bom fechamento vulvar e com mau fechamento vulvar. No entanto, não foram observadas diferenças significativas ( $p>0,05)$ nas taxas de prenhez aos 14 dias entre aquelas éguas com adequada conformação perineal e aquelas necessitando correção de defeitos quando as éguas foram agrupadas nas distintas condições reprodutivas.

\section{Discussão}

Neste estudo, entre os 344 ciclos estudados, em $45,9 \%$ dos ciclos foram observadas deficiências na conformação perineal das éguas. Foi encontrada diferença significativa ( $p$ $=0,072$ ) entre as taxas de prenhez de éguas necessitando correção de defeitos de conformação e aquelas que apresentavam boa conformação perineal (54,4\% e 63,9\%, respectivamente). Esses resultados diferem daqueles obtidos por Pascoe (1993), que observou taxas de prenhez de $34 \%$ e $66 \%$, respectivamente, para éguas não suturadas após o parto e éguas suturadas até 24 horas após o parto.

O espermatozóide é o principal fator indutor da resposta inflamatória que ocorre na égua após a cobertura (Kotilainen 
et al., 1989, Fiala et al., 2006). Essa resposta, no que diz respeito à imunidade celular, inicia 30 minutos após a cobertura, com um aumento da concentração de neutrófilos no lúmen uterino, o qual atinge o pico entre 6 e 24 horas, finalizando, após as 48 horas (Katila, 1995; Fiala et al., 2006). Essa reação é uma resposta fisiológica à presença de proteínas estranhas ao organismo (Troedsson, 1997). A égua deve ser capaz de eliminar a resposta inflamatória até o $5^{\circ}$ dia após a ovulação a fim de proporcionar ao embrião, que deve chegar ao útero nesse momento, um ambiente propício para o desenvolvimento (Asbury, 1987).

A grande maioria das éguas apresentando defeitos de conformação perineal no momento da realização da cobertura teve a correção realizada imediatamente após a ovulação. Neste momento, apesar de já em baixos teores, o principal hormônio esteróide circulante ainda é o estrógeno, fazendo com que a cérvice continue aberta e a contratilidade miometrial aumentada, o que, associado à maior atividade das glândulas endometriais na produção de muco, facilita a remoção de

\section{Referências}

ASBURY, A.C. Failure of uterine defense mechanisms. In: Robinson N.E. Current Therapy in Equine Medicine. 2 ed. Philadelphia: W.B. Saunders, 1987.

CASLICK, E.A. The vulva and the vulvo-vaginal orifice and its relation to genital health of the thoroughbred mare. Cornell Vet. v. 27, p. 178187, 1937.

FIALA, S. M.; PIMENTEL, C. A.; MATTOS, A. L. G.; GREGORY, R. M.; MATTOS, R. C. Effect of sperm numbers and concentration on sperm transport and uterine inflammatory response in the mare Theriogenology. On-line, 2006

GINTHER, O.J. Reproductive biology of the mare: basic and applied aspects. 2 ed. Cross Plains: Equiservices, 642 pp., 1992.

KATILA, T. Onset and duration of intrauterine inflammatory response in mares after insemination with fresh semen. Biol. Reprod. Mono. 1, p. 515-519, 1995.

KOTILAINEN, T.; HUHTINEN, M.; KATILA T. Sperm-induced leukocytosis in the equine uterus. Theriogenology. v. 32, p. 27-36. 1989.

JONES D.M., FIELDEN E.D., CARR D.H. Some physiological and pharmacological factors affecting uterine motility as measured by electromyographic in the mare. J. Reprod. Fertil. Supl. 44, p. 357-368, 1991. partículas da luz uterina (Neely et al., 1983; Jones et al., 1991; Leblanc et al., 1991; LeBlanc, 1997).

A correção perineal próxima à ovulação e a utilização somente de éguas clinicamente sadias provavelmente expliquem a pequena diferença existente, neste estudo, entre as taxas de prenhez obtidas nos dois grupos de éguas. Pode-se inferir que a má conformação vulvar tenha levado a um processo inflamatório com presença de neutrófilos na luz uterina e a uma maior fagocitose dos espermatozóides até atingirem as trompas, mas que não impediu completamente a ocorrência de fertilização. No entanto, grande parte das éguas deve ter sanado o processo inflamatório antes do quinto dia, permitindo que o embrião chegasse a um útero em condições de permitir o seu desenvolvimento.

Conclui-se que correções dos defeitos de períneo efetuadas antes do início do cio em que se efetuará a cobertura oferecem melhores resultados de prenhez do que quando a correção é realizada após a ovulação.

LEBLANC, M. M. Clinical considerations of endometritis. Pferdeheilkunde.v. 13, p. 538, 1997.

LEBLANC, M. M.; WARD, L.; TRAN, T.; WIDDERS, P. Identification and opsonic activity of immunoglobulins recognizing Streptococcus zooepidemicus antigens in uterine fluids of mares. J. Reprod. Fert. Supl. v. 44, p. 289-296, 1991.

NEELY, D. P.; LIU, I. K. M.; HILLMAN, R. B. Equine Reproduction. Basileia: Hoffmann-La Roche Inc., 1983, 179 p.

PASCOE, D. R. Incidence and significance of pneumovagina, foal heat mating and other management factors on the occurrence of uterine susceptibility. Equine Vet. J. v. 25, p. 187, 1993.

PASCOE, R. R. Observations on the length and angle of declination of the vulva and its relation to fertility in the mare. J. Reprod. Fertil. Supl. 27, p. 299-305, 1979.

ROSSDALE, P. D. The uterus, an organ of multiple roles. Pferdeheilkunde. v. 13, p. 427-430, 1997.

SILVA, C. A. M. Uma nova técnica para a correção cirúrgica da pneumovagina na égua. Revista Turf Fomento. v. 23, p. 247-248, 1983.

TROEDSSON, M. H. T. Therapeutic considerations for mating-induced endometritis. Pferdeheilkunde.v.13, p. 516-520, 1997. 